\title{
Trauma symptoms in children after the tsunami
}

\author{
Charini Gunaratne ${ }^{1,5}$, Peter J Kremer ${ }^{2}$, Andrew J Lewis ${ }^{3}$, Valerie Clarke ${ }^{4}$
}

Sri Lanka Journal of Child Health, 2013; 42: 192-199

\begin{abstract}
Limited research has examined factors associated with psychological distress following natural disasters among non-Western child populations. Conditions associated with trauma-related symptoms following the 2004 tsunami in a sample of 265 Sri Lankan child survivors ( $53.6 \%$ female, aged 3 to 17$)$ were examined retrospectively. Multivariate regression analyses identified pre-traumatic conditions (female gender, prior health) and peritraumatic conditions (loss of family, complete property loss) as being associated with increased trauma-related symptoms. Findings can be applied to the identification of children most at risk of developing trauma-related symptoms following a natural disaster from a non-Western population to aid development of culturally-appropriate interventions.
\end{abstract}

(Key words: children; adolescents; traumatic symptoms; tsunami; Sri Lanka)

\section{Introduction}

Every year millions of children worldwide are affected by natural or man-made disasters ${ }^{1}$. While the most prevalent disorder after a large-scale disaster is posttraumatic stress disorder (PTSD) ${ }^{2}$, the reasons for differential susceptibility to PTSD remain unclear ${ }^{3}$. A clear deficit in this area of literature is the lack of research on childhood trauma from non-Western and developing countries, particularly Sri Lanka. While trauma-related outcomes following a large-scale natural disaster have been examined in Western countries, the number of published studies on psychological effects of disasters from non-Western countries, particularly Asia, is limited ${ }^{4}$, which is concerning given that the greatest number of worldwide disasters annually occur within Asia ${ }^{5}$. The

${ }^{1}$ Sessional Academic, School of Psychology, ${ }^{2}$ Senior Lecturer, School of Exercise and Nutrition Sciences, ${ }^{3}$ Associate Professor, School of Psychology, ${ }^{4}$ Associate Professor Emeritus. School of Psychology, Deakin University, Australia, ${ }^{5}$ Lecturer, School of Psychology, Charles Sturt University, Australia

(Received on 24 March 2013: Accepted on 21 June 2013) generalisability of research findings across sociocultural and economic contexts cannot be assumed. Given that disasters such as the 2004 Indian Ocean tsunami have a significant impact on large numbers of persons, this paper will aid in identifying those individuals who are at the highest risk of developing trauma-related symptoms.

Based on a systematic review of 160 articles, researchers suggest that manifestations of PTSD arise from a combination of effects including heightened helplessness, loss of attachment figures, perceived safety and social support following a disaster ${ }^{2}$. This review found that following disaster exposure youth were at greater risk of severe impairment than adults due to youth lacking the ability to cope with the aftereffects of a disaster. Notably, the majority of the populations $(86 \%)$ included in their review and subsequent reviews ${ }^{6}$ were from developed countries.

Following the 2004 Indian Ocean tsunami considerable variation in the prevalence of PTSD in child and adolescent survivors in the months following the tsunami has been reported with rates ranging from $6-71 \%$ across populations from India ${ }^{7}$, Sri Lanka ${ }^{8}$ and Thailand ${ }^{9}$. Prevalence of other trauma-related symptoms assessed among children following the tsunami include: anxiously withdrawn behaviour $(97 \%)$ and fearfulness $(98 \%)$ in India $^{10}$, behavioural maladjustment (32\%) in Sri Lanka ${ }^{11}$ and depressive symptoms (5-11\%) in Thailand ${ }^{9}$.

Many factors are associated with symptoms following trauma exposure which are commonly grouped into pre-traumatic (e.g. demographic or social factors), peri-traumatic (e.g. factors pertaining to the event) and posttraumatic (factors which prolong symptoms after the event) conditions ${ }^{12}$. Pretraumatic factors associated with increased symptoms in child tsunami survivors include female gender ${ }^{7,10}$. A few studies have reported older children as showing more traumatic symptoms as compared to younger children ${ }^{7,9}$. Other pre-traumatic risk factors not examined in tsunami-affected children that have been associated with increased traumatic symptoms in children following other disasters, include prior trauma and prior psychopathology ${ }^{13}$. 
Within the peri-traumatic factors or types of damage and loss experienced by children following the tsunami, higher trauma exposure was associated with PTSD, depressive and anxiety symptoms ${ }^{8,14}$. The peri-traumatic factor shown to be most strongly associated with increased traumatic symptoms reported post-tsunami in children is the loss of family members ${ }^{7,8,10,14}$. Other peri-traumatic factors associated with increased traumatic symptoms in child tsunami survivors include: property damage and loss ${ }^{7,14}$, danger to one's life or to a family member's life, injury due to the tsunami and social losses such as loss/disruption of social networks ${ }^{9,14}$. Given the variability of prevalence of traumatic symptoms and risk factors across different tsunami-affected populations, it is clear that other correlates may be influencing the impact of trauma on those affected. Further, as current theory and models are formalised on Western populations, cultural differences need to be taken into consideration, thus emphasising the need for continued cross-culture research.

The current study is a community-based introductory exploration of the impact of the 2004 tsunami on a population from Sri Lanka investigating the pretraumatic and peri-traumatic factors associated with trauma-related symptoms in child survivors one month post-tsunami, derived from data extracted via a retrospective case-file analysis. It was predicted that pre-traumatic conditions (female, older age, and prior health issues) would be associated with higher levels of trauma-related symptoms. It was also predicted that peri-traumatic conditions (loss of family members, lost homes and property, witnessing the tsunami and/or sustaining injury) would be associated with higher levels of trauma-related symptoms amongst survivors after controlling for pre-traumatic conditions.

\section{Method}

This case file retrospective analysis is based on data collected during a counselling project conducted by the National Institute of Professional Counsellors in Sri Lanka one month following the tsunami, organised for 1093 adult and 631 child survivors of the tsunami residing in 19 temporary shelters and camps within the Galle District in January, $2005^{15}$. Of the individual paper files of survivors stored by the Institute, 698 de-identified files (adults $=357$, children $=305$, age missing $=36$ ) were provided to the research team. This study is based on children only. Ethical approval to conduct the current study was provided by the Deakin University Faculty of Health Human Ethics Advisory Group.
The case files were translated into English from Sinhalese by one author (CG). The accuracy of the translations was checked by another bilingual colleague and words and terminology were verified. Data were extracted from files by CG using a systematic coding approach described below. Missing values within cases were examined and variables missing more than $20 \%$ of cases were excluded. Listwise deletion was used to remove cases missing any value on the analysed variables (40 cases, $13 \%$ of total available child cases). The final sample for analysis comprised 265 children, $(53.6 \%$ were female) aged 3 to 17 years $(M=10.8$ years, $S D$ $=3.4$ ). Ethnicity was not assessed, however it was inferred the majority of the sample was Sinhalese based on the location.

Diagnostic interviews were conducted by trained counsellors employed by the counselling institute all had completed diplomas in counselling. Participant information was classified as follows.

Pre-traumatic conditions: The case file included demographics of age, gender, religion, level of education, pre-disaster health (e.g., physical ailments, diagnosed mental disorders) and social problems (e.g., bereavement, family conflicts). Among the sample, 6.4\% reported physical problems (e.g., broken limbs), 1.1\% reported mental problems (e.g., mental disabilities) and 3\% reported social problems (e.g., parental conflicts).

Peri-traumatic conditions: The participant's experience of the tsunami was described by one open-ended item, with experiences described as: witnessing the tsunami, getting caught in the waves and/or injury suffered, loss of occupation, property damage suffered, and family members lost. Within the sample, $4 \%$ witnessed the tsunami and/or were caught in the waves, and of these, injury was caused to $0.4 \%$ of the total sample.

Psychological symptoms: Trauma-related symptoms were assessed within the course of a routine clinical interview based on clinical observation conducted by counsellors. The presence of these symptoms was indicated through 11 dichotomous (no $=0$, yes $=1$ ) symptom items: stress, anxiety, depression, PTSD, suicidal thoughts, aggression, inability to cope/defeat, lack of hope, bodily aches, other physical symptoms and other symptoms. Symptoms for trauma related items were based on DSM IV diagnostic categories ${ }^{15}$; however formal diagnoses were not made.

Coding for pre-traumatic categorical variables was: gender $(0=$ male, $1=$ female $)$; education $(0=$ up to 
primary school, $1=$ up to middle school, $2=$ up to secondary school $)$ and religion $(0=$ non-Buddhist, 1 $=$ Buddhist ). Pre-existing health and social problems were recoded into a new variable, 'prior problems' $(0$ = no prior problems, 1 = prior problems $)$. Peritraumatic categorical variables were coded as: the amount of property damage $(0=$ no property damage, 1 = some property damage, 2 = complete loss of property) and number of family members lost $(0=$ loss of no family members, 1 = loss of one or more family members). Witnessing the tsunami or being injured was recoded into a new variable 'witness/injury' ( $0=$ did not witness/were injured, 1 $=$ witness/injury). The peri-traumatic variable for property loss was dichotomized $(0=$ none to some property loss, 1 = complete property loss).

Descriptive analyses (means, proportions) were used to summarise the sample demographics and survivor characteristics. Traumatic symptoms were summed up for analysis and scored from 0-11. Conditions associated with trauma-related symptom groups were examined using Chi-square analyses. Multiple linear regression was used to test for associations between pre-traumatic and peri-traumatic conditions and traumatic symptom score. Crude and adjusted regression models were run for each of the pretraumatic and peri-traumatic variables. To test the unique contribution of the pre-traumatic and peritraumatic conditions on trauma-related symptoms, the pre-traumatic and peri-traumatic variables respectively were entered in sequential blocks with the symptom score as the outcome variable. All analyses were conducted using SPSS (version 17.0). Alpha was set at $p<0.05$.

\section{Results}

The characteristics of the child survivor sample are presented in Table 1.

Table 1

Child demographic characteristics (pre-traumatic conditions) \& reported loss \& damage (peri-traumatic conditions)

\begin{tabular}{|l|c|}
\hline \multicolumn{1}{|c|}{ Characteristic } & N= 265 \\
\hline Age, mean years (SD) & $10.8(3.4)$ \\
\hline Gender, \% female & 53.6 \\
\hline Education, \% up to a primary school education (Year 5) & 47.9 \\
\hline Religion, \% Buddhist & 98.1 \\
\hline Prior health issues, \% existing issues prior to tsunami & 11.3 \\
\hline Damage, \% no damage & 2.6 \\
\hline Witness/Injury, \% witnessed tsunami/injured & 4.5 \\
\hline Property damage, \% complete lost property & 54.3 \\
\hline Family members, \% lost one or more family members & 4.9 \\
\hline
\end{tabular}

Almost half of the sample was aged 8-12 years and $34 \%$ were aged 13-17 years. Almost half had up to a primary school education and $11 \%$ reported some prior physical, mental or social issues. More than half of all child survivors completely lost their homes and property while $5 \%$ lost one or more family members.

Figure 1 shows the proportion of survivors displaying the assessed traumatic symptoms.

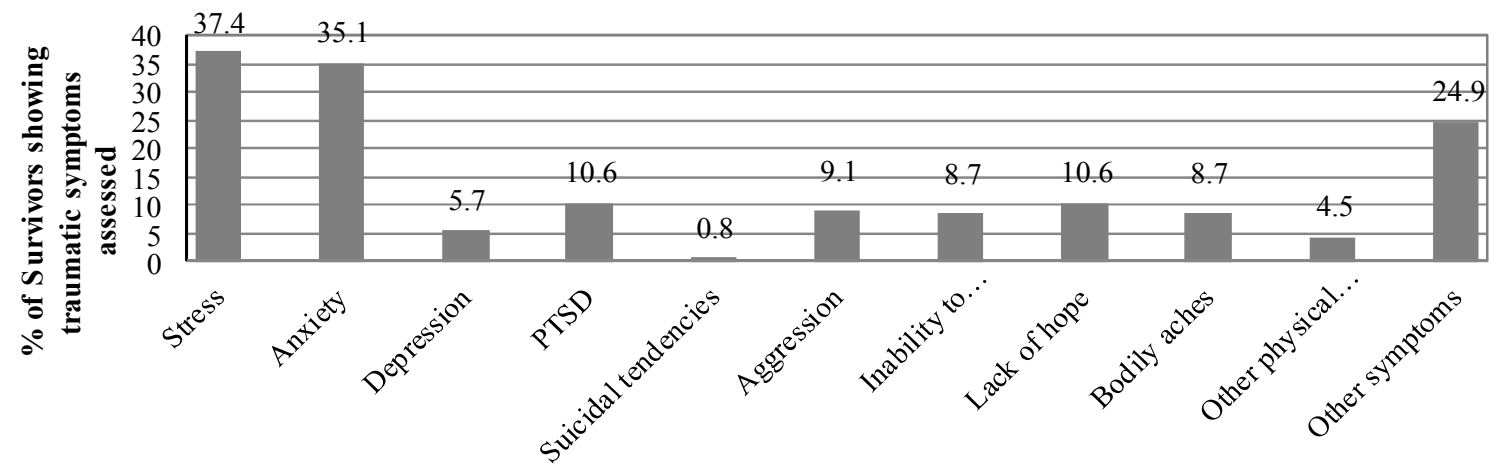

Figure 1: Percentage of survivors showing each traumatic symptom assessed 
Over $35 \%$ of children were assessed as having stress symptoms, 35\% having anxiety symptoms and less than $1 \%$ having suicidal tendencies.

Figure 2 shows the relative proportions for total number of symptoms for all survivors. The majority reported either none or one or two symptoms
(70.6\%), and about a third (29.4\%) reported three or more symptoms.

The characteristics of children displaying traumatic symptoms are presented in Table 2. Traumatic symptoms were associated with loss of one or more family members.

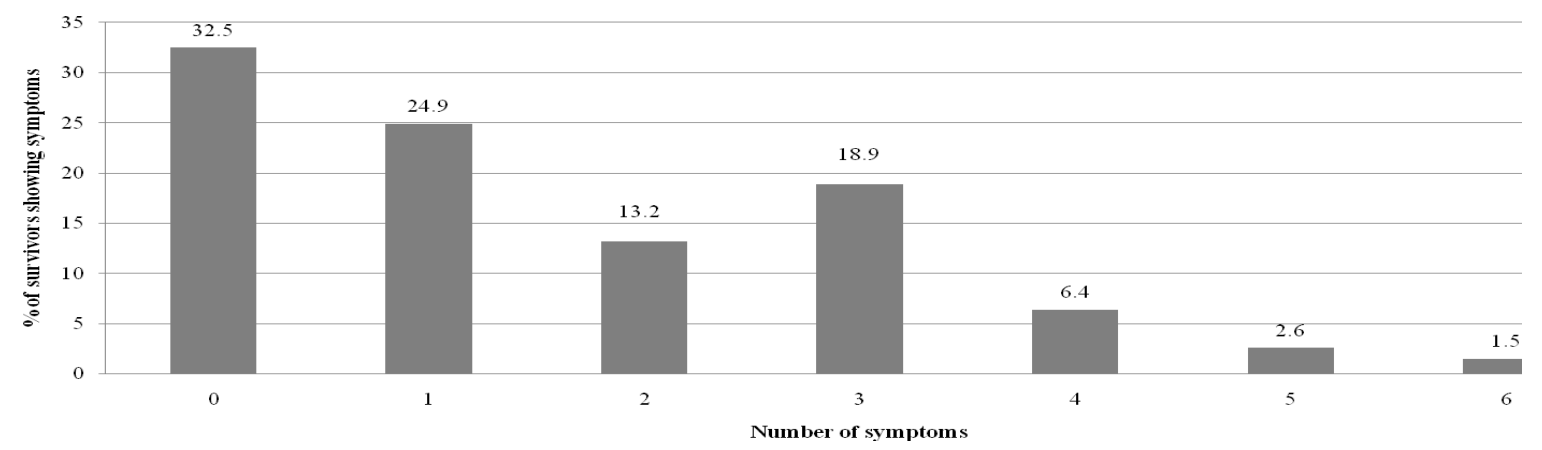

Figure 1: Percentage of survivors distributed by the number of traumatic symptoms shown

Table 2: Characteristics of traumatic symptom groups

\begin{tabular}{|c|c|c|c|c|}
\hline & $\begin{array}{c}0 \text { traumatic } \\
\text { symptoms }(n=86) \\
\text { Number }(\%)\end{array}$ & $\begin{array}{c}1-2 \text { traumatic } \\
\text { symptoms }(n=101) \\
\text { Number }(\%) \\
\end{array}$ & $\begin{array}{c}\geq 3 \text { traumatic } \\
\text { symptoms }(n=78) \\
\text { Number }(\%)\end{array}$ & $\chi^{2}$ \\
\hline \multicolumn{5}{|l|}{ Pre-traumatic condition } \\
\hline $\begin{array}{l}\text { Gender } \\
\text { Male } \\
\text { Female }\end{array}$ & $\begin{array}{l}45(36.6) \\
41(28.9)\end{array}$ & $\begin{array}{l}47(38.2) \\
54(38.0)\end{array}$ & $\begin{array}{l}31(25.2) \\
47(33.1)\end{array}$ & 2.6 \\
\hline $\begin{array}{l}\text { Age in years } \\
3-7 \\
8-11 \\
12-17\end{array}$ & $\begin{array}{l}12(25.5) \\
35(33.3) \\
39(34.5)\end{array}$ & $\begin{array}{l}19(40.4) \\
40(38.1) \\
42(37.2)\end{array}$ & $\begin{array}{l}16(34.0) \\
30(28.6) \\
32(28.3)\end{array}$ & 1.4 \\
\hline $\begin{array}{l}\text { Education } \\
\text { Up to a primary school } \\
\text { Up to a middle school } \\
\text { Up to a secondary school }\end{array}$ & $\begin{array}{l}35(27.6) \\
29(36.7) \\
22(22.0) \\
\end{array}$ & $\begin{array}{l}51(40.2) \\
28(35.4) \\
22(37.3) \\
\end{array}$ & $\begin{array}{l}41(32.3) \\
22(27.8) \\
15(25.4) \\
\end{array}$ & 2.8 \\
\hline $\begin{array}{l}\text { Religion } \\
\text { Buddhist } \\
\text { Other (Hindu, Muslim, Christian) }\end{array}$ & $\begin{array}{l}84(32.3) \\
02(40.0) \\
\end{array}$ & $\begin{array}{c}100(38.5) \\
01(20.0)\end{array}$ & $\begin{array}{l}76(29.2) \\
02(40.0) \\
\end{array}$ & 1.0 \\
\hline $\begin{array}{l}\text { Prior health issues } \\
\text { No prior issues } \\
\text { Existing issues prior to tsunami }\end{array}$ & $\begin{array}{l}78(33.2) \\
08(26.7)\end{array}$ & $\begin{array}{l}92(39.1) \\
09(30.0) \\
\end{array}$ & $\begin{array}{l}65(27.7) \\
13(43.3) \\
\end{array}$ & 3.2 \\
\hline Peri-traumatic condition & & & & \\
\hline $\begin{array}{l}\text { Witness/Injury } \\
\text { Did not witness/was injured } \\
\text { Witnessed/was injured }\end{array}$ & $\begin{array}{l}84(33.2) \\
02(16.7)\end{array}$ & $\begin{array}{l}96(37.9) \\
05(41.7) \\
\end{array}$ & $\begin{array}{l}73(28.9) \\
05(41.7) \\
\end{array}$ & 1.6 \\
\hline $\begin{array}{l}\text { Property damage } \\
\text { No property damage } \\
\text { Some property damage } \\
\text { Complete loss of property }\end{array}$ & $\begin{array}{l}05(27.8) \\
36(35.0) \\
45(31.3) \\
\end{array}$ & $\begin{array}{l}08(44.4) \\
48(46.6) \\
45(31.3) \\
\end{array}$ & $\begin{array}{l}05(27.8) \\
19(18.4) \\
54(37.5) \\
\end{array}$ & $11.7^{*}$ \\
\hline $\begin{array}{l}\text { Loss of family members } \\
\text { No loss of family } \\
\text { Lost one/more members }\end{array}$ & $\begin{array}{l}85(33.7) \\
01(07.7)\end{array}$ & $\begin{array}{l}97(38.5) \\
04(30.8)\end{array}$ & $\begin{array}{l}70(27.8) \\
08(61.5) \\
\end{array}$ & $7.6^{*}$ \\
\hline
\end{tabular}

Note: $* p<.05, * * p<.01, * * * p<.001$ 
Results of the multiple regression analyses are shown in Table 3.

Table 3

Regression model predicting traumatic symptoms in child tsunami survivors from Sri Lanka based on pretraumatic and peri-traumatic conditions

\begin{tabular}{|l|c|c|}
\hline & $\begin{array}{c}\text { Crude Coefficient } \\
\boldsymbol{B}(\boldsymbol{S E})\end{array}$ & $\begin{array}{c}\text { Adjusted Coefficient } \\
\boldsymbol{B}(\boldsymbol{S E})\end{array}$ \\
\hline Pre-traumatic Condition & \multicolumn{1}{c|}{} \\
\hline Gender & $0.4(0.2)$ & $0.4(0.2)^{*}$ \\
\hline Age & $-0.3(0.2)$ & $-0.2(0.2)$ \\
\hline Prior Health Issues & $0.6(0.3)$ & $0.7(0.3)^{*}$ \\
\hline Peri-traumatic Condition & & \\
\hline Witness/Injury & $0.8(0.4)$ & $0.6(0.4)$ \\
\hline Complete loss of property & $0.3(0.2)$ & $0.4(0.2)^{*}$ \\
\hline Loss of one or more family members & $1.5(0.4)^{* * *}$ & $1.7(0.4)^{* * *}$ \\
\hline
\end{tabular}

Note: ${ }^{*} p<.05,{ }^{* *} p<.01,{ }^{* * *} p<.001$

Results of the unadjusted analyses indicated that the peri-traumatic condition, loss of family members, was associated with trauma-related symptoms; specifically, loss of a family member was associated with higher symptom scores. In the adjusted analyses, the pre-traumatic conditions significantly associated with trauma-related symptoms were female gender and pre-existing health issues; specifically female children and children with pre-existing health issues showed increased trauma-related symptoms as compared to their counterparts. When the pretraumatic conditions were controlled, the peritraumatic conditions of loss of family members and complete loss of property were significantly associated with trauma-related symptoms; specifically children who lost one or more family members and who completely lost their property showed increased trauma-related symptoms as compared to their counterparts. The final model with both the pre-traumatic and peri-traumatic variables accounted for $9 \%$ of the variance in trauma-related symptoms $\left(R^{2}=.11\right.$, adjusted $\left.R^{2}=.09\right)$ was significant $(F(6,258)=5.42, p<.001)$.

\section{Discussion}

This study investigated whether pre-traumatic and peri-traumatic conditions were associated with increased trauma-related symptoms in Sri Lankan child survivors assessed one month after the 2004 tsunami. The study found pre-traumatic conditions associated with trauma-related symptoms to be female gender and having prior health problems. After controlling for pre-traumatic variables, the peritraumatic factors of complete loss of home and property and losing one or more family members were associated with trauma-related symptoms in children.
Based on a non-Western sample, our finding that girls showed increased traumatic symptoms as compared to boys is consistent with the majority of research based on Western populations ${ }^{16}$. Research has also shown that following trauma exposure girls are more likely to report internalizing symptoms while boys tend to report externalizing symptoms ${ }^{17}$. However, in the current sample, a higher proportion of females than males reported aggressive symptoms. Such an increase in aggression in females might be compared to the finding that after Hurricane Katrina, girls were reported to display greater difficulty than boys regulating their emotional responses ${ }^{18}$.

Our study also found that children with prior health issues showed increased traumatic symptoms as compared to children without these health issues. Previous research has shown increased psychopathology is associated with physical, social and mental factors in adolescents exposed to trauma from Western ${ }^{19}$ and non-Western countries $^{20}$. However, our finding of an association between prior health problems and increased traumatic symptoms has not been previously reported. This finding may reflect an increased vulnerability to the traumatic effects of a major disaster in the context of preexisting health vulnerability suggesting that the finding is best understood in terms of a cumulative stress model ${ }^{21}$.

In this study, while the association between age and traumatic symptoms was not significant, preschool aged children presented with the highest percentages of traumatic symptoms when compared to primary school aged children and adolescents. Previous research has not clarified whether preschool aged children $^{22}$, primary school-aged children ${ }^{23}$ or adolescents ${ }^{9}$ are more susceptible to the effects of a 
traumatic event. Different rates of symptoms in preschool children in our study suggest that younger children may be at increased risk for developing traumatic symptoms following trauma exposure.

It has been widely discussed that the current diagnosis for PTSD in preschool aged children is not sufficiently sensitive and alternative criteria to those in the DSM-IV have been used to diagnose traumatized preschool aged children; when revised criteria were utilised, the prevalence of PTSD was $25-26 \%$ compared to being zero when DSM-IV criteria were used ${ }^{22}$. Research following the tsunami indicated that older children were more likely to develop traumatic symptoms using measures based on DSM-IV criteria 9 . Little is known about the traumatic impact of the tsunami on the preschool aged child survivors and further research examining this population using age-appropriate measures is needed to more accurately identify the impact of traumatic events on younger children. Young children are not likely to display classical PTSD symptoms and these criteria require cognitive and linguistic competencies which are not available to a young child. Instead young children tend to show withdrawn or agitated responses to stressors which often present as if they were internalising or externalising problems ${ }^{24}$.

Children who lost one or more family members and who suffered the complete loss of property showed increased traumatic symptoms as compared with their counterparts. It is of interest that we did not find that children who witnessed the tsunami or were injured reported increased traumatic symptoms, contrary to previous literature ${ }^{9}$. Other research has found a dose effect of trauma exposure, namely increased trauma exposure following a natural disaster to be associated with increased traumatic symptoms ${ }^{25}$. In our sample it is noteworthy that despite over half of the child survivors losing homes and property, children were far more impacted by the loss of a loved one. These findings suggest that for children losses of significant attachment figures caused much greater impact than property losses. Children who lost property and homes are likely to have their parents to act as buffers to the impact of such material losses. By contrast, children who have lost a parent are obviously in a highly vulnerable circumstance without a known source of comfort and security.

A comprehensive account of pre-traumatic conditions also needs to take into consideration cultural, historical and political factors. It could be argued that natural disasters in developing countries are more likely to produce PTSD due to the magnitude of the loss of resources that is associated with such disasters ${ }^{26}$. Such loss of resources may impede community capacity to respond to child survivors of the tsunami and alleviate their symptoms, potentially compounding the difficulties impacting on their current and future mental health ${ }^{27}$.

It is clear however that the impact of a major traumatic event on a child population from a developing country is complex. This study has focused only on examining the direct exposure of such an event and subsequent symptoms in children. While the current study attempts to take some pretraumatic conditions into consideration, the conditions examined were limited to the data included in the counselling records. In addition the records were based on a Western-model of trauma. While PTSD has been found within survivor populations, whether PTSD is the most suitable construct of posttraumatic distress in children and adolescents from Sri Lanka is questionable ${ }^{28}$. Other limitations of the current study include the crosssectional design which does not allow for examining predictive effects, the restrictive convenience sample which does not allow for generalising to other contexts, and the lack of direct recording of ethnicity.

Examination of the impact of a natural disaster in a non-Western population is significant. Natural disasters are as unpredictable as they are devastating. It is essential that researchers continue to investigate the impact of natural disasters in different cultures in order to optimise effects to promote recovery, care and treatment programmes. By identifying the high risk groups for traumatic symptoms and factors associated with increased symptoms in survivors, intervention can be targeted to those groups. It is critical that intervention programs be culturally appropriate in order to maximise their success in alleviating the mental health burden of people from developing countries.

\section{References}

1. Masten AS, Osofsky JD. Disasters and their impact on child development: Introduction to the special section. Child Development 2010; 81(4): 1029-39.

http://dx.doi.org/10.1111/j.14678624.2010.01452.x

2. Norris FH, Friedman MJ, Watson PJ. 60,000 disaster victims speak: Part II. Summary and implications of the disaster mental health research. Psychiatry. 2002; 65(3): 240-60. http://dx.doi.org/10.1521/psyc.65.3.240.20169 
3. Cahill SP, Foa EB. Psychological theories of PTSD In: Friedman MJ, Terence M. Keane, Resick PA, editors. Handbook of PTSD: Science and practice. New York, NY US: Guilford Press; 2007. p. 55-77.

4. Udomratn P. Mental health and the psychosocial consequences of natural disasters in Asia. International Review of Psychiatry 2008; 20(5): 441-4.

http://dx.doi.org/10.1080/09540260802397487

5. Norris FH. Summary and overview of disasters in developing countries In: Marsella AJ, Johnson JL, Watson PJ, Gryczynski J, eds. Ethnocultural perspectives on disaster and trauma: Foundations, issues, and applications. New York: Springer Science + Business Media; 2008.

6. Neria Y, Nandi A, Galea S. Post-traumatic stress disorder following disasters: A systematic review. Psychological Medicine 2008; 38(4): 467-80.

http://dx.doi.org/10.1017/S0033291707001353

7. John PB, Russell S, Russell PSS. The prevalence of posttraumatic stress disorder among children and adolescents affected by tsunami disaster in Tamil Nadu; Disaster Management \& Response: DMR: An Official Publication of the Emergency Nurses Association 2007; 5(1): 3-7.

8. Neuner F, Schauer E, Catani C, Ruf M, Elbert T. Post-tsunami stress: A study of posttraumatic stress disorder in children living in three severely affected regions in Sri Lanka. Journal of Traumatic Stress 2006; 19(3): 339-47. http://dx.doi.org/10.1002/jts.20121

9. Thienkrua W, Cardozo BL, Chakkraband MLS, Guadamuz TE, Pengjuntr W, Tantipiwatanaskul $\mathrm{P}$, et al. Symptoms of posttraumatic stress disorder and depression among children in tsunami-affected areas in Southern Thailand. Journal of the American Medical Association 2006; 296(5): 549-59.

http://dx.doi.org/10.1001/jama.296.5.549

10. Bhushan B, Kumar JS. Emotional distress and posttraumatic stress in children surviving the 2004 tsunami Journal of Loss and Trauma 2007; 12(3): 245 - 57.

http://dx.doi.org/10.1080/15325020600945996
11. Agampodi TC, Agampodi SB, Fonseka P. Prevalence of mental health problems in adolescent schoolchildren in Galle District, Sri Lanka. Asia Pacific Journal of Public Health 2011; 23(4): 588-600. http://dx.doi.org/10.1177/1010539509349866

12. Vogt DS, King DW, King LA. Risk pathways for PTSD: Making sense of the literature. In: Friedman MJ, Keane TM, Resick PA, editors. Handbook of PTSD: Science and practice. New York, NY US: Guilford Press; 2007. p. 99-115.

13. Vernberg EM, Varela RE. Posttraumatic stress disorder: A developmental perspective. In: Vasey MW, Dadds MR, editors. The developmental psychopathology of anxiety. New York, NY US: Oxford University Press; 2001. p. 386-406.

14. Wickrama KAS, Kaspar V. Family context of mental health risk in tsunami-exposed adolescents: Findings from a pilot study in Sri Lanka. Social Science and Medicine 2007; 64(3): 713-23. http://dx.doi.org/10.1016/j.socscimed.2006.09.03 $\underline{1}$

15. Ranawaka DS, Dewaraja R. Tsunami counselling project of the Sri Lanka National Institute of Professional Counsellors. In: Kubo C, Kuboki T, editors. Psychosomatic medicine: Proceedings of the 18th World Congress on Psychosomatic Medicine; 2005 August 21 - 26; Kobe, Japan. New York, NY US: Elsevier Science; 2006. p. 79-81.

16. Armour C, Elhai JD, Layne CM, et al. Gender differences in the factor structure of posttraumatic stress disorder symptoms in warexposed adolescents. Journal of Anxiety Disorders 2011; 25(4): 604-11. http://dx.doi.org/10.1016/j.janxdis.2011.01.010

17. Ostrov E, Offer D, Howard KI. Gender differences in adolescent symptomatology: A normative study. Journal of the American Academy of Child and Adolescent Psychiatry 1989; 28(3): 394-8. http://dx.doi.org/10.1097/00004583-198905000$\underline{00016}$

18. Marsee MA. Reactive aggression and posttraumatic stress in adolescents affected by Hurricane Katrina Journal of Clinical Child and Adolescent Psychology 2008; 37(3): 519-29. 
19. Doron-LaMarca S, Vogt DS, King DW, King LA, Saxe GN. Pretrauma problems, prior stressor exposure, and gender as predictors of change in posttraumatic stress symptoms among physically injured children and adolescents. Journal of Consulting and Clinical Psychology 2010; 78(6):7 81-93.

20. Russell S, Subramanian B, Russell PS, Nair MK. Psychopathology, traumatic life events, and coping skills among patients attending a primary-care adolescent clinic. Indian Journal of Pediatrics 2012; 79 Suppl 1: S52-59. http://dx.doi.org/10.1007/s12098-011-0437-6

21. Gunnar MR, Frenn K, Wewerka SS, Van Ryzin MJ. Moderate versus severe early life stress: Associations with stress reactivity and regulation in 10-12-year-old children Psycho-neuroendocrinology 2009; 34(1): 62-75. http://dx.doi.org/10.1016/j.psyneuen.2008.08.01 $\underline{3}$

22. Scheeringa MS, Zeanah CH. Reconsideration of harm's way: Onsets and comorbidity patterns of disorders in preschool children and their caregivers following Hurricane Katrina. Journal of Clinical Child and Adolescent Psychology 2008; 37(3): 508-18.

http://dx.doi.org/10.1080/15374410802148178

23. McDermott B, Palmer L. Postdisaster emotional distress, depression and event-related variables: findings across child and adolescent developmental stages. Australia and New Zealand Journal of Psychiatry 2002; 36(6): 754 61.

http://dx.doi.org/10.1046/j.14401614.2002.0109 $\underline{0 . x}$
24. Lewis AJ, Olsson CA. Early Life Stress and Child Temperament Style as Predictors of Childhood Anxiety and Depressive Symptoms: Findings from the Longitudinal Study of Australian Children. Depression Research and Treatment. 2011; 2011.

25. Catani C, Gewirtz AH, Wieling E, Schauer E, Elbert T, Neuner F. Tsunami, war, and cumulative risk in the lives of Sri Lankan schoolchildren. Child Development 2010; 81(4): 1176-91. http://dx.doi.org/10.1111/j.14678624.2010.0146 $\underline{1 . \mathrm{X}}$

26. Norris FH, Slone LB. The epidemiology of trauma and PTSD. In: Friedman MJ, Keane TM, Resick PA, editors. Handbook of PTSD: Science and practice. New York, NY US: Guilford Press; 2007. p. 78-98.

27. Pine DS, Cohen JA. Trauma in children and adolescents: risk and treatment of psychiatric sequelae. Biological Psychiatry 2002; 51(7): 519. http://dx.doi.org/10.1016/S0006-3223(01)01352$\underline{\mathrm{X}}$

28. Fernando GA, Miller KE, Berger DE. Growing pains: The impact of disaster-related and daily stressors on the psychological and psychosocial functioning of youth in Sri Lanka. Child Development 2010; 81(4): 1192-210. 